\title{
Trans-Pacific whole mantle structure
}

\author{
Lijun Liu, ${ }^{1,2}$ Ying Tan, ${ }^{1}$ Daoyuan Sun, ${ }^{3}$ Min Chen, ${ }^{4}$ and Don Helmberger ${ }^{1}$ \\ Received 3 August 2010; revised 21 January 2011; accepted 26 January 2011; published 13 April 2011.
}

[1] Recent reports on modeling USArray data reveal mostly vertical microplates with little resemblance to preliminary reference Earth model (PREM). Such complexity at plate boundaries makes it difficult to form reliable images of ocean basins using global paths. Here, we report on modeling stacked seismograms obtained from the first broadband array (TriNet) situated on the edge of the Pacific Plate, southern California, with no major subduction zone blocking its view. Extended records, including multi-S and $\mathrm{ScS}$ waves up to four bounces from 18 Tonga-Fiji deep events $(140$ to $620 \mathrm{~km})$ are analyzed to check the validity of existing models and derive the whole mantle shear velocity structure along this corridor. Synthetics generated from 3-D tomographic models do not fit the upper mantle triplication data or the mantle reverberations associated with the $\mathrm{ScS}$ multiples as well as the 1-D model PAC06. We construct a hybrid model (HPAC), which remains one dimensional down to $800 \mathrm{~km}$ (PAC06). The lower portion of HPAC is essentially the tomography model S20RTS with velocity variation inflated by a factor of 2 for the lowermost $600 \mathrm{~km}$. Thus, the mid-Pacific large low shear velocity province (LLSVP) has a lower shear velocity of about $2 \%$ relative to PREM and extends into the midmantle, similar to that beneath South Africa. Moreover, rapid changes in the differential (ScS-S) and $(\mathrm{ScS} 2-\mathrm{S})$ times as a function of distance suggest ultra low velocity zones near the eastern edge and under the LLSVP, again similar to that found beneath Africa.

Citation: Liu, L., Y. Tan, D. Sun, M. Chen, and D. Helmberger (2011), Trans-Pacific whole mantle structure, J. Geophys. Res., 116, B04306, doi:10.1029/2010JB007907.

\section{Introduction}

[2] Seismic velocity structures of the deep mantle are essential in developing an understanding of its chemical composition, thermal states and dynamics. Our knowledge of this region has expanded greatly with the development of seismic tomography from which we see not only the largescale low seismic velocity structures underneath Africa and Western Pacific and high-velocity belt correlated with ancient subduction zones [Su et al., 1994], but also fine structures like subducted oceanic slabs [van der Hilst et al., 1997; Grand, 2002; Li et al., 2008] and deep-rooted mantle plumes [Montelli et al., 2004; Nolet et al., 2007]. Resolution of such features in the mantle beneath oceans, however, has been restricted due to the limited amount of ray coverage, which is also where existing tomography models bear the most inconsistency.

[3] One example of these uncertain regions is the Pacific Basin (Figure 1a), where global seismic tomography suffers

\footnotetext{
${ }^{1}$ Seismological Laboratory, California Institute of Technology, Pasadena, California, USA.

${ }^{2}$ Now at IGPP, University of California, San Diego, La Jolla, California, USA.

${ }^{3}$ Carnegie Institution of Washington, Washington, D. C., USA.

${ }^{4}$ Department of Earth Atmospheric and Planetary Sciences, Massachusetts Institute of Technology, Cambridge, Massachusetts, USA.

Copyright 2011 by the American Geophysical Union. 0148-0227/11/2010JB007907
}

from inadequate sampling and resolving power. Differences in choice of seismic phases and source information during the tomographic inversion lead to different images of the trans-Pacific structure, especially those of the lowermost mantle. For example, comparison of two global shear wave tomography models [Ritsema et al., 2004; Grand, 2002] (Figure 1b) along the Tonga-California corridor displayed in Figure 1a indicates that although the lateral position of the Pacific large low shear velocity province (LLSVP) above the core-mantle boundary (CMB) seems well constrained, the radial distribution of the LLSVP still bears significant variations. A more detailed comparison of several more tomography models along the same cross section (see Figure S1 of Text S1 of the auxiliary material) further confirms this observation, with the main difference among these images being the vertical extent of the LLSVP above the CMB. ${ }^{1}$ If we define the LLSVP as velocity anomalies lower than $-1.5 \%$, the imaged height of this structure varies from a few $100 \mathrm{~km}$ (e.g., models TXBW and S20RTS) to $\sim 1000 \mathrm{~km}$ above the CMB (e.g., models S362D1 and SB4L18, Figure S1). These differences stem from inadequate data coverage and choices of a priori model parameterization. Specifically, the large source-receiver distances across the Pacific Ocean $\left(>70^{\circ}\right)$ lead to very flat lower mantle ScS and $S$ raypaths (Figure $1 b$ ), which only sample a very thin layer (a couple hundreds $\mathrm{km}$ ) of the lowermost mantle above the

\footnotetext{
${ }^{1}$ Auxiliary materials are available in the HTML. doi:10.1029/ 2010JB007907.
} 
A

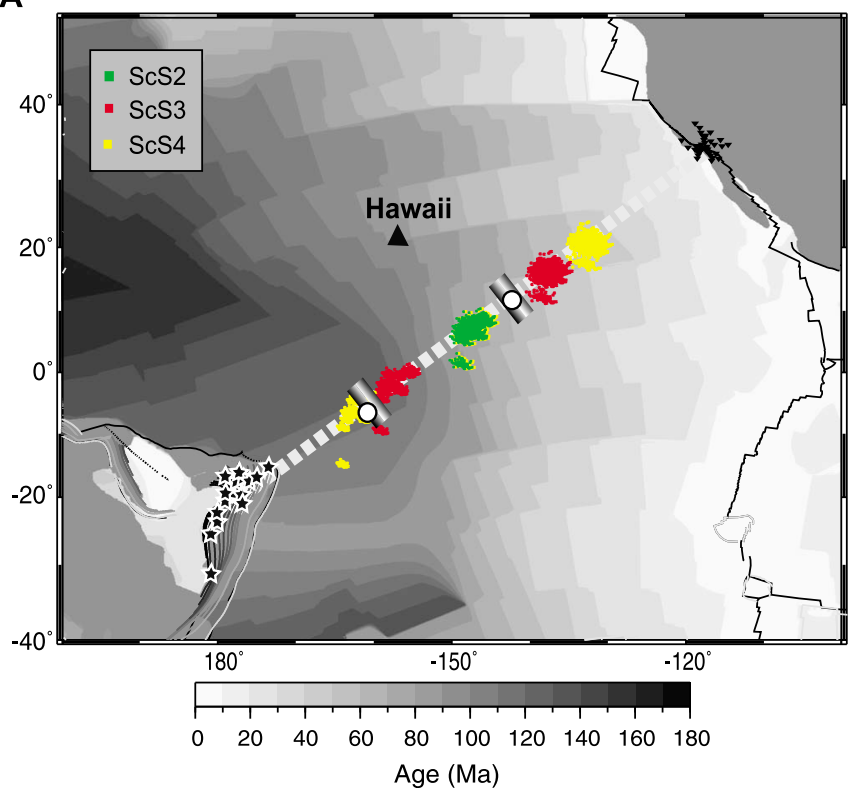

B

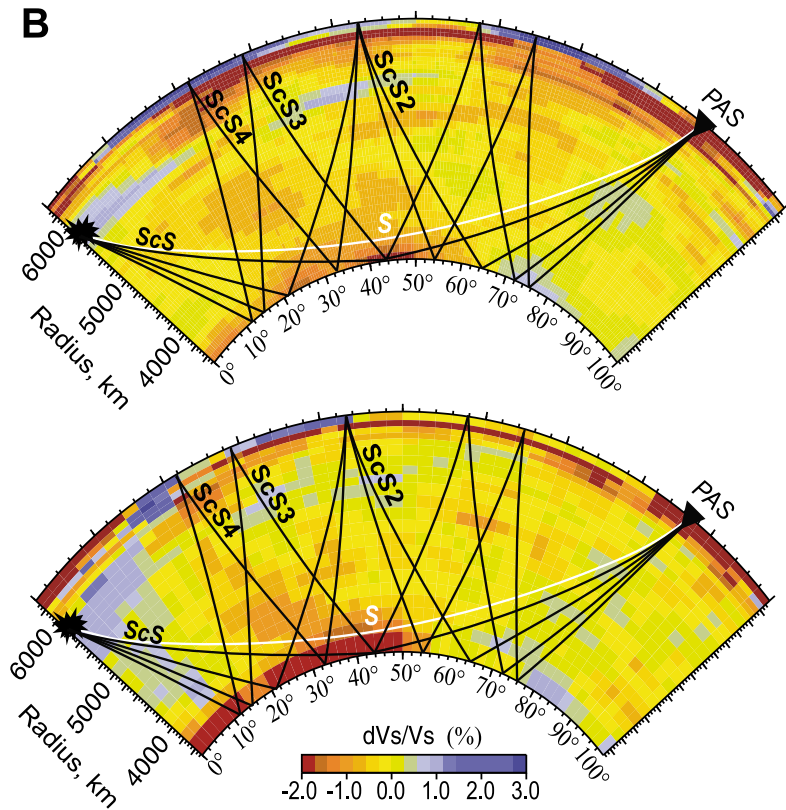

Figure 1. Location and tomography images of the Pacific corridor for this study. (a) Surface bounce point locations of ScS multiples overlying the age distribution of the Pacific seafloor. The thick dashed line approximates a 2-D corridor from Fiji-Tonga to California. The small triangles and stars at the two ends of the corridor indicate the TriNet array and events, respectively. The solid cylinders along the corridor represent the lateral location of the two ultra low velocity zones (ULVZ) on the core-mantle boundary, and the two white dots represent ULVZs inferred by other studies (refer to text for details). (b) Mantle structure of the cross section below the corridor revealed by two different tomography models (top, S20RTS; bottom, TXBW). Multibouncing ScS raypath from the event on 15 August 2000 (Table 1) to Pasadena (PAS) sample the lower mantle, especially the Pacific LLSVP. The actual sampling is 3 orders of magnitude denser than plotted.

CMB. Given that these are the most commonly used phases in global tomographic inversions across the Pacific, it is not surprising that the radial structure of the LLSVP is not well resolved. One analogy is to locate an earthquake using a regional array, where the inferred source depth usually carries greater uncertainty than the horizontal locations because of the overall 2-D distribution of stations. Consequently, both the geometry and magnitude of heterogeneity associated with the Pacific LLSVP, and hence its dynamics, remain unclear.

[4] In contrast, regional studies, focusing on shallower depth, have much better constraints on pure path properties, where the recovered models are also similar [Grand and Helmberger, 1984; Gaherty and Jordan, 1996; Melbourne and Helmberger, 2001]. More recently, Tan and Helmberger [2007] used the broadband data from Fiji-Tonga events recorded at the dense TriNet array to study the upper mantle shear structure along the Tonga-California corridor (Figure 1a). By fitting both the travel time and waveforms of the multibouncing $\mathrm{S}$ phases from a large number of events at different depths with densely sampled upper mantle triplicated paths (Figure 2a), they obtained a one-dimensional shear velocity mantle model (PAC06) down to the depth of $800 \mathrm{~km}$ where it joins PREM (Figure 2b). The largest difference between PAC06 and PREM is the crustal thickness, 8 versus $20 \mathrm{~km}$, and the presence of the $220 \mathrm{~km}$ discontinuity in PREM which is not in PAC06. This discontinuity is partially removed in S20RTS [Ritsema et al., 2004], with the addition of the thick slow zone (Figure 1b) at depths between 100 and $200 \mathrm{~km}$ and the addition of a 3-D crustal correction. If we average S20RTS along the 2-D section, we obtain the dashed line in Figure $2 \mathrm{~b}$, which is much closer to PAC06, as discussed by Tan and Helmberger [2007].

[5] In order to obtain a better image of the lower mantle, especially the LLSVP structure, this study extends the upper mantle study by Tan and Helmberger [2007] down to the lower mantle. Consequently, we hope to develop a data set for testing dynamic models for the mid-Pacific LLSVP where various parameterizations of chemistry can be investigated, similar to what has been done for the African LLSVP [Sun et al., 2007]. In this case, they used synthetics generated from a metastable thermal-chemical convection model, and predicted the observed waveform directly. Such paths are not available in the Pacific, but we can use a well-calibrated $(\mathrm{ScSn}-\mathrm{S})$ data set as a substitute for sampling the LLSVP.

\section{Data and Method}

[6] We selected 18 events occurring between 2000 and 2007 in Fiji-Tonga (Table 1). This is the same study area as that of Tan and Helmberger [2007] with some common events used in both studies. The broadband seismographs are from the California TriNet stations (Figure S2), which combined with the sources produce 1200 source-receiver pairs. In a map view (Figure 1a), all event-receiver great circle paths stay within a narrow band with little azimuthal 


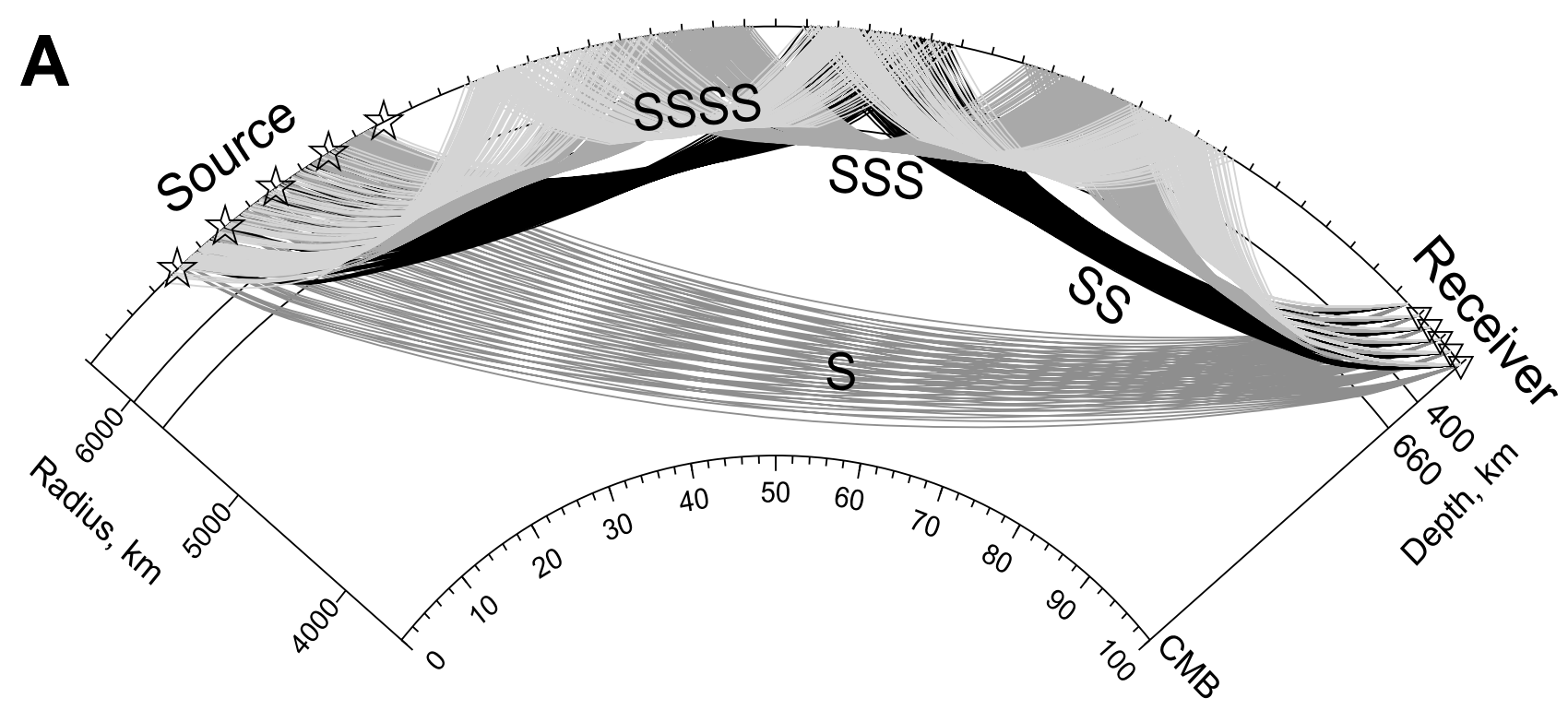

B

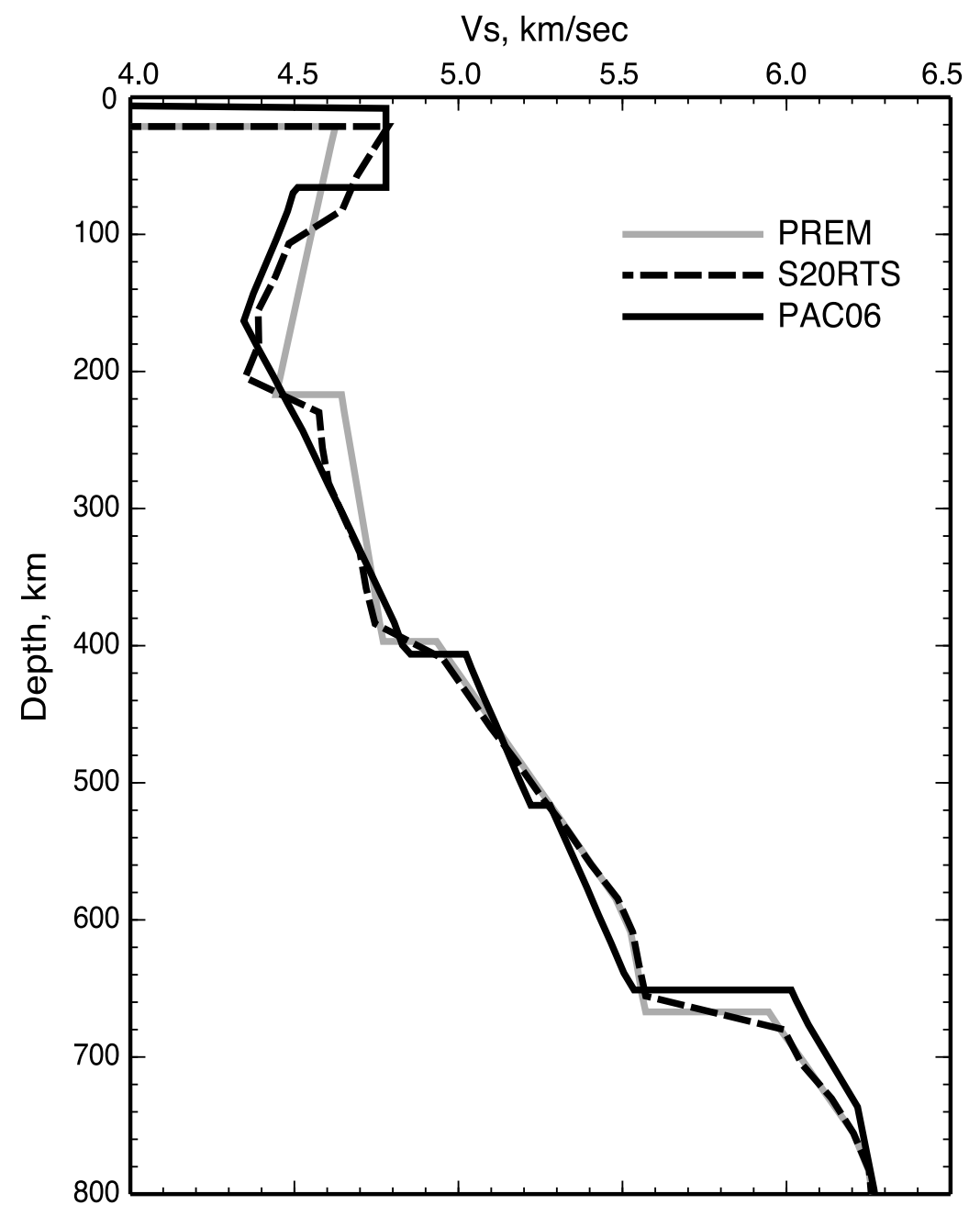

Figure 2. (a) The dense sampling of the Pacific upper mantle by $\mathrm{S}$ multiples. (b) Velocity models (SH) proposed for the upper mantle along this Pacific corridor. The gray line represents PREM, the dashed line is a horizontal average of S20RTS, and the dark line is the 1-D model PAC06 by Tan and Helmberger [2007]. 
Table 1. Source Parameters of the Events Used from Harvard's CMT Catalog

\begin{tabular}{lcccc}
\hline \multicolumn{1}{c}{ Date } & Origin Time & $\begin{array}{c}\text { Latitude/Longitude } \\
(\mathrm{deg})\end{array}$ & $\begin{array}{c}\text { Depth } \\
(\mathrm{km})\end{array}$ & $\mathrm{M}_{\mathrm{w}}$ \\
\hline 8 Jan 2000 & $1647: 20.60$ & $-16.92 /-174.25$ & 160 & 6.5 \\
14 Jun 2000 & $0215: 25.84$ & $-25.52 / 178.05$ & 605 & 5.9 \\
15 Aug 2000 & $0430: 09.00$ & $-31.50 / 179.70$ & 358 & 6.7 \\
28 April 2001 & $0449: 53.00$ & $-18.00 /-177.10$ & 351 & 6.1 \\
4 Jul 2001 & $0706: 31.00$ & $-21.70 /-176.70$ & 186 & 5.9 \\
12 Sep 2001 & $0848: 37.00$ & $-21.00 /-179.20$ & 608 & 6.4 \\
4 Jan 2003 & $0515: 03.00$ & $-20.60 /-177.70$ & 377 & 6.5 \\
14 Mar 2003 & $1254: 12.00$ & $-17.30 /-175.30$ & 275 & 6.1 \\
12 Jun 2003 & $0859: 20.00$ & $-5.90 / 154.70$ & 185 & 6.2 \\
27 Jul 2003 & $0204: 10.00$ & $-21.00 /-176.60$ & 200 & 5.8 \\
11 Jan 2004 & $0929: 09.00$ & $-20.10 /-179.20$ & 672 & 5.3 \\
25 Jan 2004 & $1143: 12.00$ & $-16.70 /-174.20$ & 143 & 6.6 \\
15 Jul 2004 & $0427: 10.00$ & $-17.50 /-179.00$ & 560 & 7.1 \\
17 Nov 2004 & $2109: 13.00$ & $-20.00 /-178.80$ & 620 & 6.6 \\
19 Mar 2005 & $1734: 45.00$ & $-21.90 /-179.60$ & 590 & 6.3 \\
2 Jan 2006 & $2213: 40.00$ & $-19.90 /-178.20$ & 583 & 7.2 \\
2 Feb 2006 & $1248: 43.00$ & $-17.80 /-178.40$ & 598 & 6.7 \\
26 Feb 2006 & $0308: 27.00$ & $-23.60 /-180.00$ & 536 & 6.4 \\
\hline
\end{tabular}

variations $\left(<5^{\circ}\right)$, making this trans-Pacific corridor an ideal 2-D profile for constraining the whole mantle structure. All the events selected have source depths greater than $140 \mathrm{~km}$ and excite clear upper mantle $\mathrm{S}$ and lower mantle $\mathrm{ScS}$ reverberation phases. Due to the large epicentral distances $\left(\sim 80^{\circ}\right)$, all cases show clear reverberations up to ScS4. The lower mantle, therefore, is densely sampled by these multiples (Figure $1 \mathrm{~b}$ ). The actual ray sampling of the lower mantle structure, however, is almost 3 orders of magnitude denser than that illustrated in Figure 1b, because of the size of TriNet and the sampling by 18 events distributed in depth.

[7] The objective of this study is to extend our upper mantle study to the lower mantle, whose velocity structures can be constrained by the multibouncing ScS phases. We first validate the upper mantle model PAC06 with the new $\mathrm{ScS}$ reverberation data reported in this paper, and then we focus on a hybrid approach that combines PAC06 with the best variant of the existing tomographic models for the lower mantle.

\section{Waveform Validation for PAC06}

[8] A particularly convincing method for validating models constrained by travel times is to compare synthetics against the waveform data. Another method is to test how well a model can fit data not used in the construction of the model. Here, we apply both approaches. Although there are a number of methods for generating synthetics, the recently developed 3-D spectral element method (SEM) [Komatitsch and Tromp, 2002] has many advantages especially for complete records.

[9] Figure 3 displays the comparison of waveform modeling for one event (010428) with the 1-D PAC06 (Figure 3a) and the 3-D S20RTS model (Figure 3b), where we plot the $\mathrm{S}$ and $\mathrm{ScS}$ multibouncing phases. Both data and synthetics are aligned on SS phase since it is chosen as the reference in modeling multi-S waves to minimize the effect of errors in events' origin time and location [Tan and Helmberger, 2007]. The data are stacked such that each record represents the average of the nearest records within $20 \mathrm{~km}$. Most of the model fitting is on the western edge of the TriNet array, $75.8^{\circ}$ to $78^{\circ}$ for this event, where the fast lid structure is still intact [i.e., Melbourne and Helmberger, 2001; Tanimoto and Sheldrake, 2002]. Moreover, the stacking in the middle of the array obviously reduces the noise, especially at later times when the $\mathrm{S}$ multiples are well developed and the various triplication branches can be weak. While these upper mantle phases are fit quite well with PAC06, the timing for the $\mathrm{ScS}$ multiples are too early (Figure 3a), since PREM is assumed at depths greater than $800 \mathrm{~km}$ (Figure 2). In contrast, synthetics from the S20RTS model do not predict the upper mantle triplications as well, but do a better job of matching the ScS multiples (Figure 3b), which were included in the S20RTS tomography inversion. Note that the construction of S20RTS, especially its upper mantle, also involved fitting other data sets, i.e., surface wave dispersion and normal mode splitting [Ritsema et al., 2004]. Ideally one should validate model PAC06 against these data, but it becomes much more difficult to test the full 3-D structure along this corridor.

[10] Another way to validate the structure of this 2-D corridor is to check its predictions against independent data sets. Here we look at the upper mantle sensitive precursors (S660-S, S410-S, and s660-S, etc.) and the peg legs (S660+S, $\mathrm{sS} 660+\mathrm{S}$, etc.) of multi-ScS waves whose raypaths are displayed in Figure 4a, following the notation of Revenaugh and Jordan [1991]. Both the timing and amplitude of these internal reflections as predicted by the 1-D PAC06 model agree with the data quite well (Figure $4 \mathrm{~b}$ ). Note that this data set was not used in deriving PAC06 and becomes an independent check. Assuming lateral homogeneity of the upper mantle along the corridor, we might expect the amplitudes of the reverberations to grow relative to the $\mathrm{ScSn}$, as the order (n) gets bigger due to redundancy (Figure 4a). Although this is generally observed, there are some complications because the events are not on the surface. Thus the depth phases $(\mathrm{sScSn})$ have better constructive interference but are also more likely to sample the slab structure in the source region [Tan and Helmberger, 2007]. In Figure S3, we include three other events at different depths that fit both the precursors and peg legs equally well although several arrivals are a few seconds off when displayed on a larger scale. In general, PAC06, constrained by upper mantle phases from over 40 events [Tan, 2006], predicts these reverberations well.

[11] In contrast, predictions of these secondary phases from the 3-D model S20RTS are off (Figure 4c). The precursors from S20RTS are too early $(8 \mathrm{~s})$ and the peg legs are too late $(10 \mathrm{~s})$. Since these precursors and peg legs are the most sensitive to the upper mantle, we conclude that the S20RTS upper mantle is too slow along this particular corridor. Consequently, the trade-off between the upper and lower mantle velocity structures suggests that this part of S20RTS lower mantle must be too fast, since it is forced to fit the multiple $\mathrm{ScS}$ phases (Figure 3b). Similarly, the upper mantle in the tomography model TXBW also seems too slow, as indicated by the travel time data discussed in the next section.

[12] In order to refine the Pacific lower mantle structure, we will take advantage of the well-constrained upper mantle (PAC06), and combine PAC06 with existing tomography 


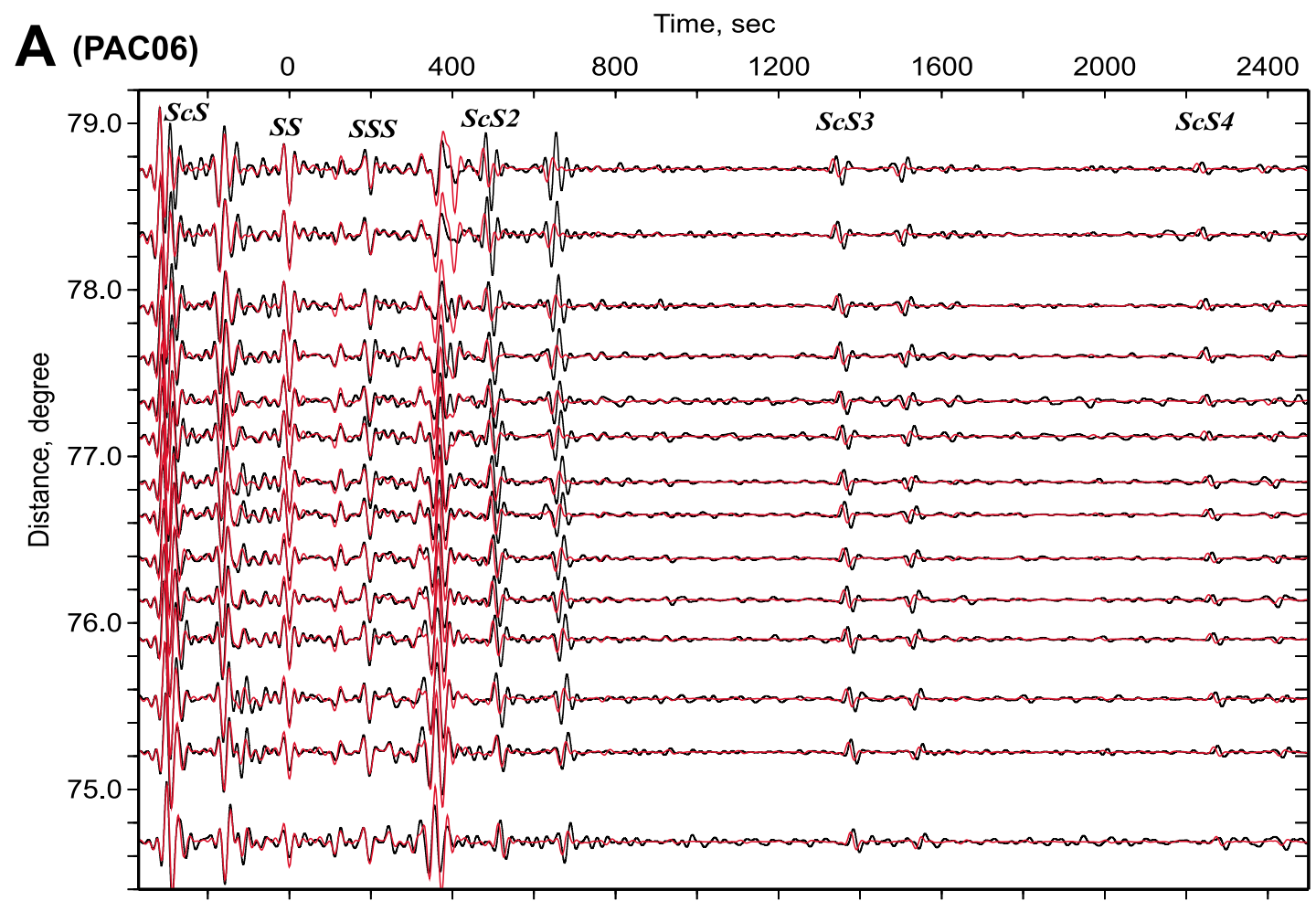

\section{B (S20RTS)}

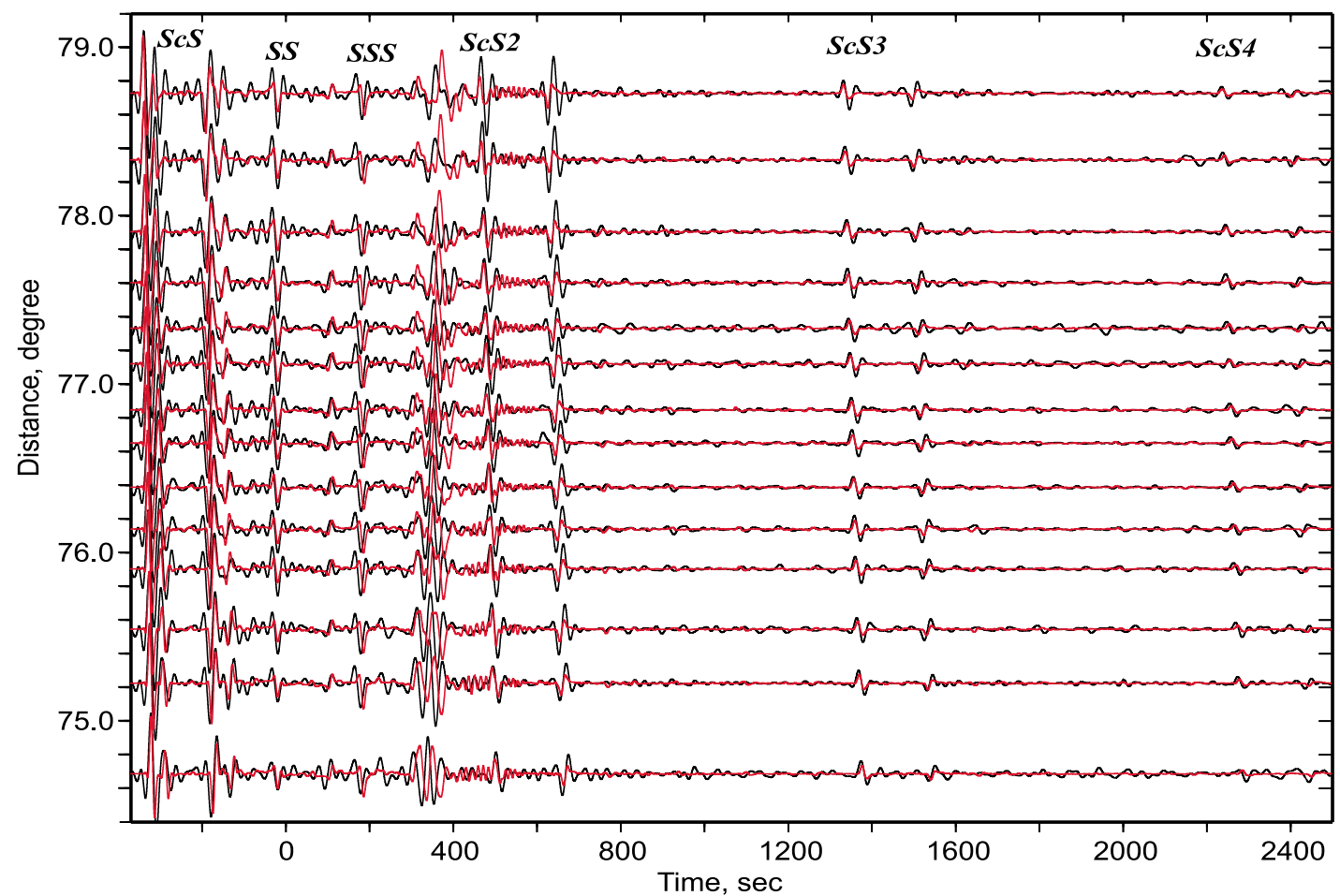

Figure 3. Synthetic seismograms based on (a) the 1-D model PAC06 and (b) the 3-D tomography model S20RTS for the event on 28 April 2001 (Table 1), where red lines are synthetics and black are data. All seismograms are aligned on SS including the S reverberations and ScS multibouncing phases (up to ScS4). Both data and synthetics have a band pass of 10-100 s. A running stack algorithm is applied to bring up upper mantle multiples (refer to text). 
A

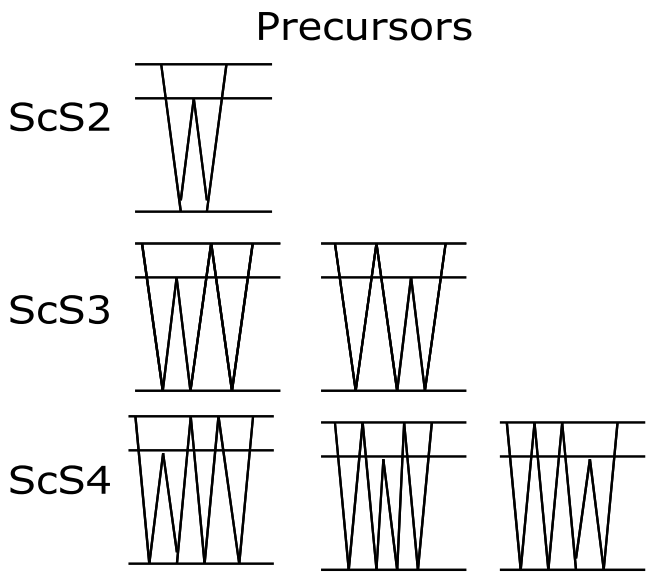

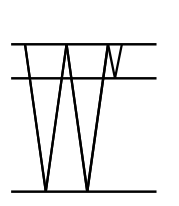

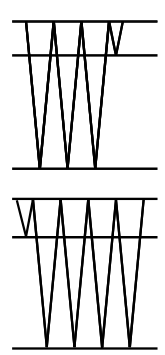

Peglegs
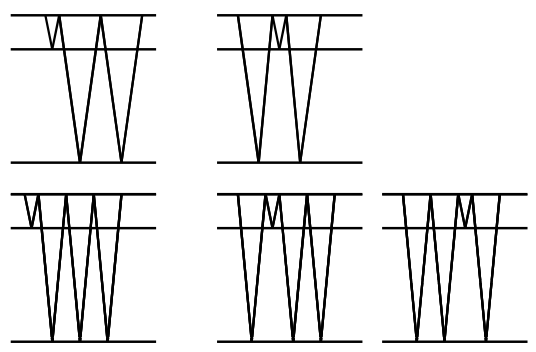

B

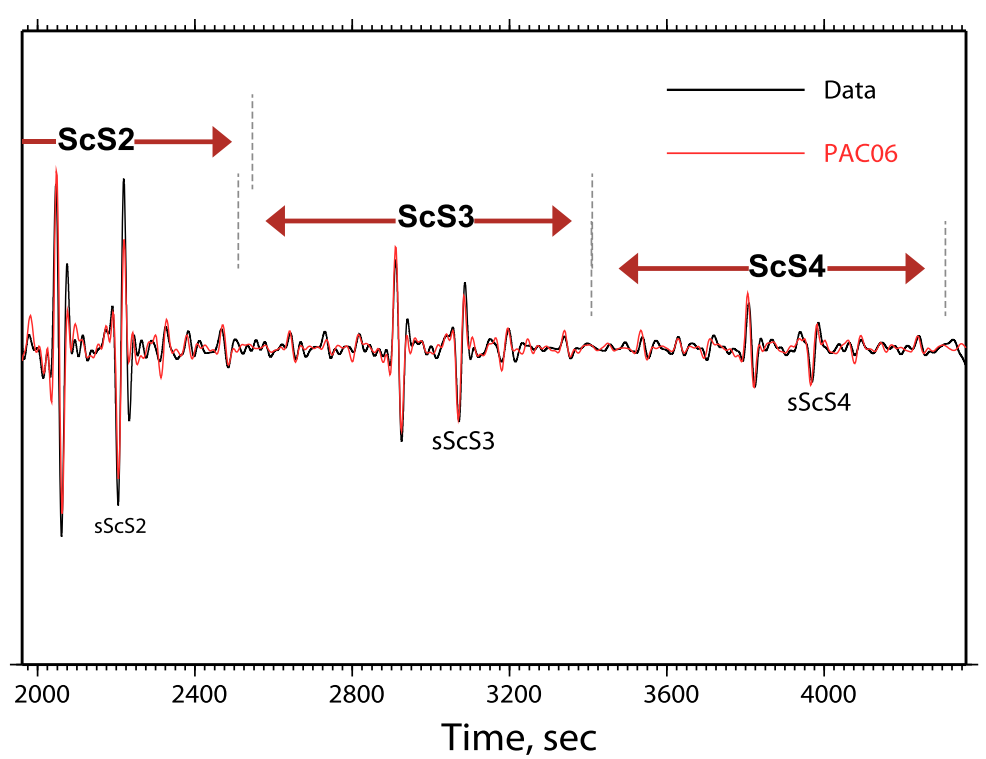

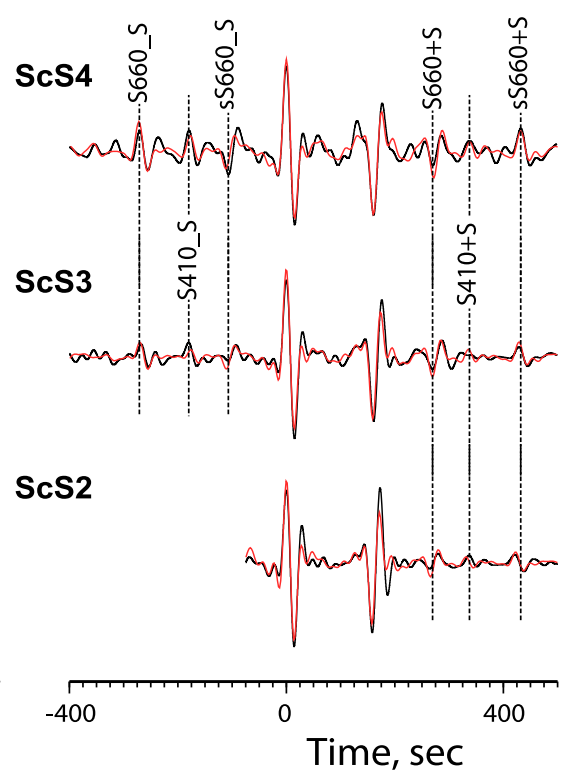

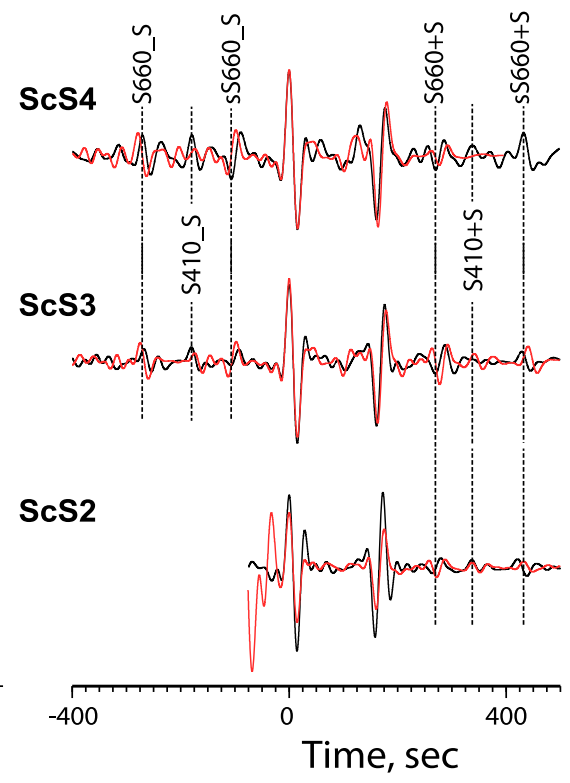

Figure 4. (a) Predicted ScS multiples and their precursors and peg legs based on (b) PAC06 and (c) S20RTS for the event on 28 April 2001 (Table 1). All phases are aligned on ScS3 on the left and on individual ScS multiples in the zoomed-in plots on the right. Red is synthetics, and black is data. 
models (e.g., S20RTS and TXBW) to generate a hybrid whole mantle model. By adjusting the magnitude and pattern of lower mantle seismic anomalies, we attempt to better match the ScS multiples.

\section{Pacific LLSVP Structure}

[13] WKM synthetics [Ni et al., 2000] for the various ScS multiples generated from either the 1-D PAC06 model, the 3-D tomography models, or the hybrid models display very little waveform distortions, so we condensed our efforts to matching the timing differentials determined by cross correlations of data against synthetics. Three types of models were examined, including (1) the PAC06 + PREM lower mantle, (2) the original 3-D tomography models (S20RTS in Figure 5a and TXBW in Figure 5b), and (3) a hybrid model with PAC06 + lower mantle of the tomography models.

[14] For the 1-D model 1, we see a systematic increase of residual magnitudes toward higher multiples (black symbol in Figure 5). This implies the lower mantle along this profile is in general slower than PREM, while longer raypath leads to greater delays in travel time. The amount of delay, however, is not a linear function of the order of reverberations, indicating that the lower mantle structure cannot be represented by a 1-D model that allows for simple superposition. Since the multiple core phase residuals suggest existence of lateral heterogeneities in the lower mantle rather than 1-D layering effects, we started with existing tomography models (S20RTS and TXBW) to fit these anomalies. The predicted residuals are shown with dark gray symbols in Figures 5a and 5b, respectively. Both tomography models minimize the residuals for $\mathrm{ScS}$ and $\mathrm{ScS} 2$ phases, but the higher multiples predicted by S20RTS show negative residuals (Figure 5a) and those by TXBW even more negative (Figure $5 \mathrm{~b}$ ). This indicates that these tomography models are overall too slow for the multiple core phases. In contrast, all the residuals being negative from the original tomography models turn positive for the hybrid model (light gray symbols in Figure 5), suggesting that the tomography lower mantles are too fast. Consequently, this implies that the upper mantle of both tomography models is too slow, confirming our conclusion from waveform validations.

[15] The observed travel time anomalies among all the multiples suggest that to better fit the residual data, we need to slow down the lower mantle by enhancing the anomalies in part or all of the tomography models. Since existing tomography models display much more discrepancies in the vertical extent of the LLSVP than in the lateral direction (Figure S1), we prefer applying such enhancements more in the radial direction than in the horizontal, conforming to the common features in these tomography models. To understand the trade-off between the velocity enhancing factor and the height above $\mathrm{CMB}$, we have conducted a two-parameter search process where the root-mean-square (RMS) travel time residuals from all $\mathrm{ScS}$ multiples are to be minimized while the algebraic mean of these residuals are forced to vanish. In effect, we look for a model that not only produces the smallest residuals for all multiples, but also balances all the differentials so that the scatter of residuals is the smallest. Because higher multiples also sample the LLSVP more densely and, therefore, have a stronger constraint on its velocity structure, we first exclude the $\mathrm{ScS}$ data that is heavily affected by localized features (e.g., ultra low velocity zones (ULVZs), see the next section) rather than the broad-scale structure.

[16] The searching process is presented in Figure 6a based on the above tomography models. We also provide a plot for the sensitivity and trade-off between the enhancement factor $f$ and inflation height $h$ (Figure S4). Tests with different $f$ values for positive and negative anomalies indicate that the LLSVP is the dominant feature in the study region, with slab-like structures having a very minor effect on total travel times. We find that the best fit occurs with $\mathrm{f}=3.02$ at an $\mathrm{h}=500 \mathrm{~km}$ for the TXBW hybrids (model Hybrid3), and with $\mathrm{f}=1.9$ at an $\mathrm{h}=600 \mathrm{~km}$ for S20RTS hybrids (model Hybrid4). The models based on S20RTS produce systematically smaller scatter (RMS residuals) than those based on TXBW. This is because the latter didn't include multiple $\mathrm{ScS}$ in its inversion and, therefore, the spatial distribution of inferred structures is less well constrained.

[17] The resulting travel time residuals based on the two best fitting models are shown in Figure $6 \mathrm{~b}$, which further demonstrates that predictions from the TXBW-based model are less well balanced among different multiples compared to those based on S20RTS. In this exercise, the best fitting model for ScS multiples is Hybrid4 based on S20RTS. The structure of this hybrid model is shown in Figure S5a, where the uppermost $800 \mathrm{~km}$ is represented by the 1-D model PAC06, the middle mantle is the original tomography model S20RTS, and the lowermost $600 \mathrm{~km}$ is the tomography enhanced by a factor of $\sim 2$. In short, our new lower mantle model has a super plume (LLSVP) structure roughly $600 \mathrm{~km}$ high, with an average velocity reduction of $\sim 2 \%$.

\section{Ultra Low Velocity Zones}

[18] Besides the overall travel time residuals, the data sets, especially $\mathrm{ScS}$ and $\mathrm{ScS} 2$, also display considerable scatter (or trend), which is difficult to explain (Figure 5). Specifically, the shift for $\mathrm{ScS}-\mathrm{S}$ is about $1 \mathrm{~s}$ per degree occurring over a window of less than $5^{\circ}$, and a similar trend exists for $\mathrm{ScS} 2-\mathrm{S}$ although with a more complex pattern. Some of the trend could be caused by event mislocation, but working with differential residuals should help eliminate most of it [Grand and Helmberger, 1984]. Some of it could be caused by the complex structure beneath the receiver array [Melbourne and Helmberger, 2001]. This second possibility can be checked by plotting the events recorded by the same station (Figure S6). Since most stations show similar distance dependence for $\mathrm{ScS}-\mathrm{S}$ and its multiples, this trend in residual times must be independent of receiver-side structures. A similar exercise can be performed to check the effect of source-side structures, by plotting records at all stations from the same event (Figure S7). Since events with significantly different depths, and therefore, raypaths, also show similar distance dependence for all $\mathrm{ScS}$ multiples, we conclude that these trends must be caused by the lower mantle structure. These trends exist for all four types of models we have examined (Figures 5, 6, and 7), indicating that none of these models captures the corresponding structure.

[19] Plots of the ScS raypaths (Figure 1b) indicate that the ScS bounce point moves slightly to the right for increasing distance and that $\mathrm{ScS}$ samples the edge of the mid-Pacific LLSVP near $50^{\circ}$. This quasi-linear trend in ScS-S residuals 

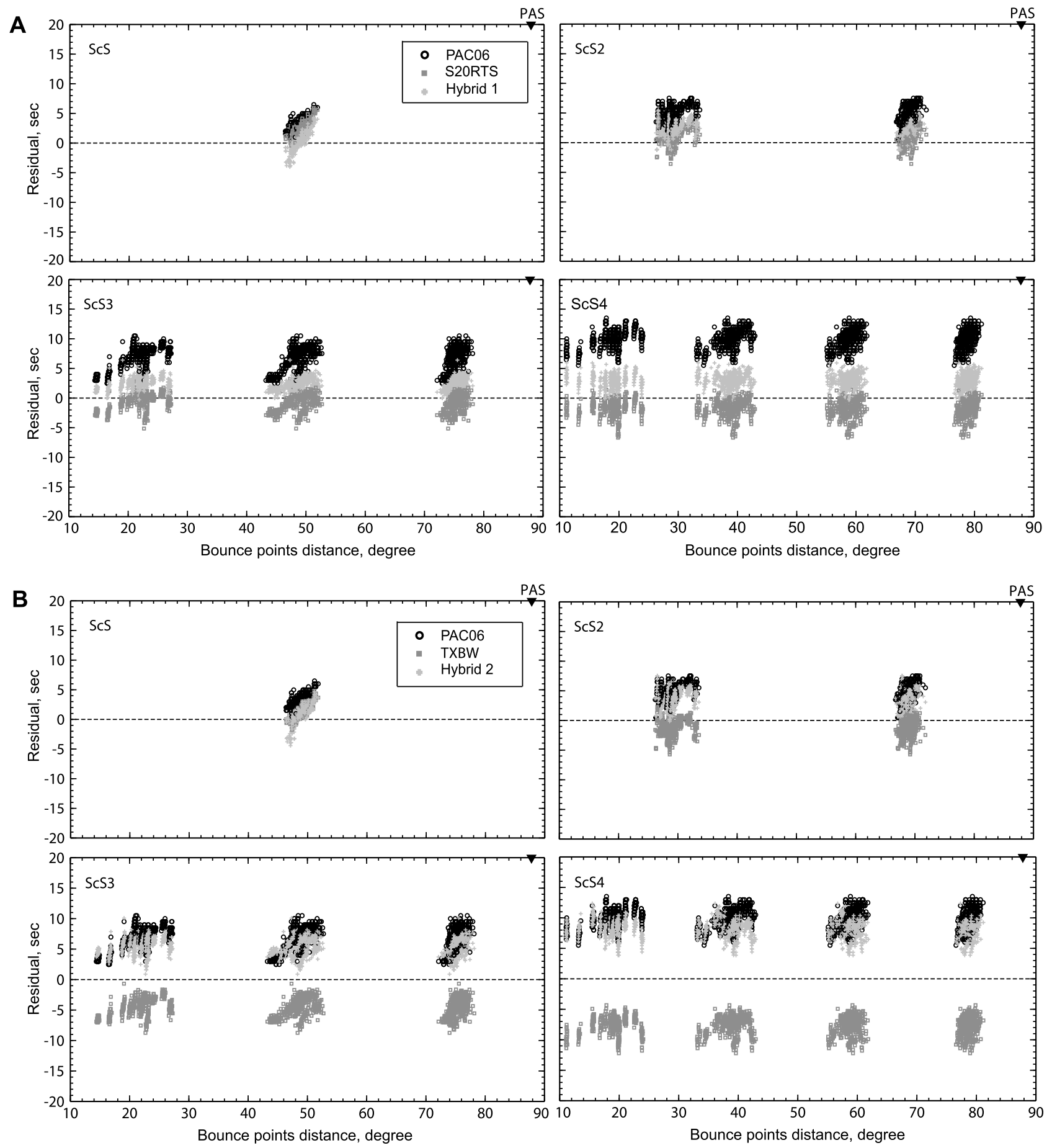

Figure 5. The differential travel time residuals (data and synthetics) of $\mathrm{ScS}$ multiples based on three velocity models: PAC06 (black circle), original tomography models (gray square; (a) S20RTS, (b) TXBW), and the hybrid of PAC06 and tomography models (light gray plus sign). See text for the construction of these hybrid models. The horizontal axis shows the CMB bounce point locations of each source-receiver couple (each corresponds to one symbol in the plot) with the station PAS shown for reference.

requires a sharp structure sampled by $\mathrm{ScS}$ but not by $\mathrm{S}$. From the raypath shown in Figure 1b, we conclude that this structure should be around the $\mathrm{ScS}$ bounce points on the CMB. By assuming a simple geometry (triangle) of this structure, we find that an ultra low velocity zone (ULVZ) near the edge of the LLSVP can explain the timing issue best (Figures S5b and S8). Such a feature can largely flatten out the scatter in $\mathrm{ScS}$ although we would expect some waveform distortions [Sun and Helmberger, 2008], which, in this study, are hard to observe due to the close vicinity of 

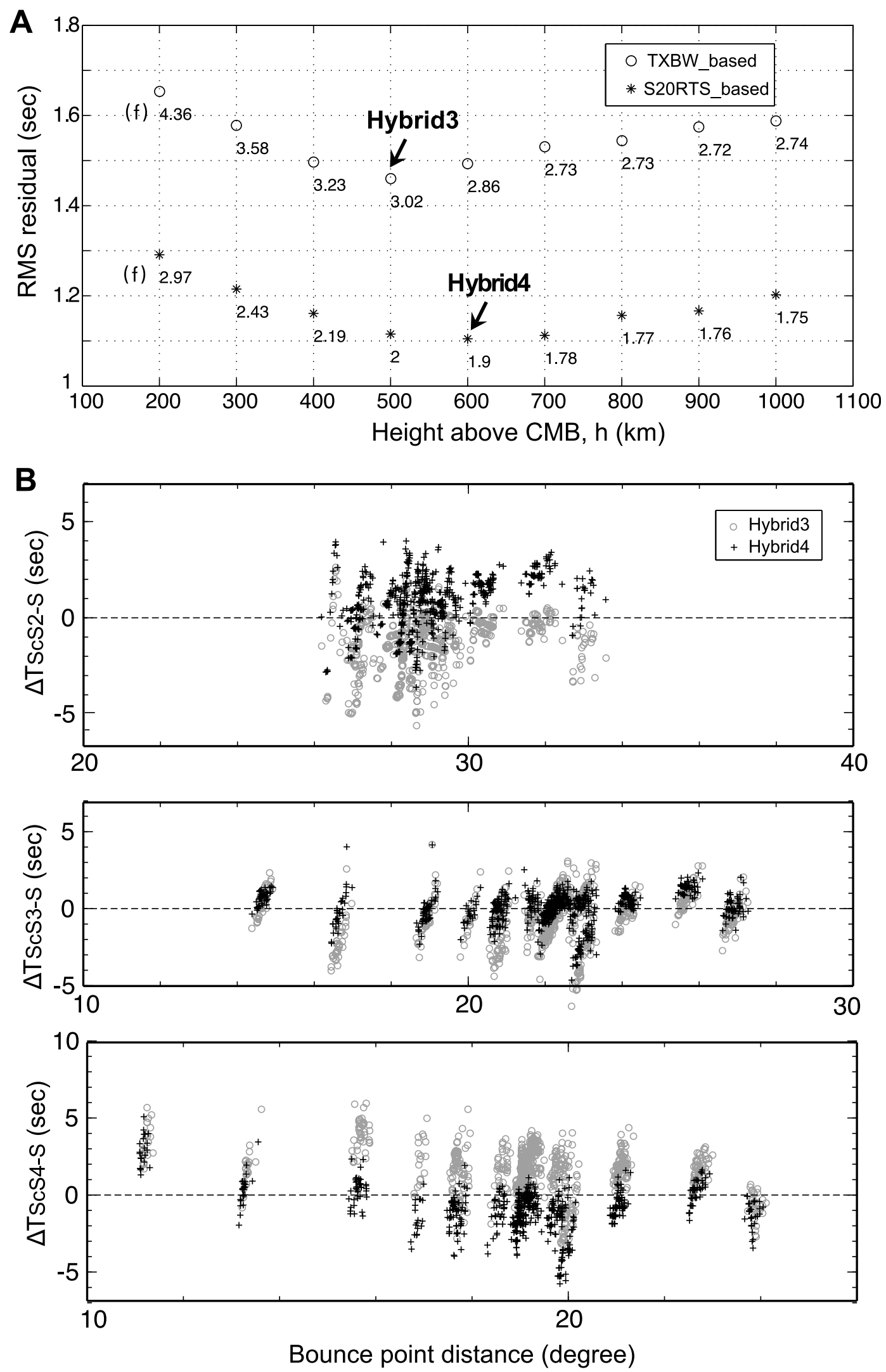

Figure 6 

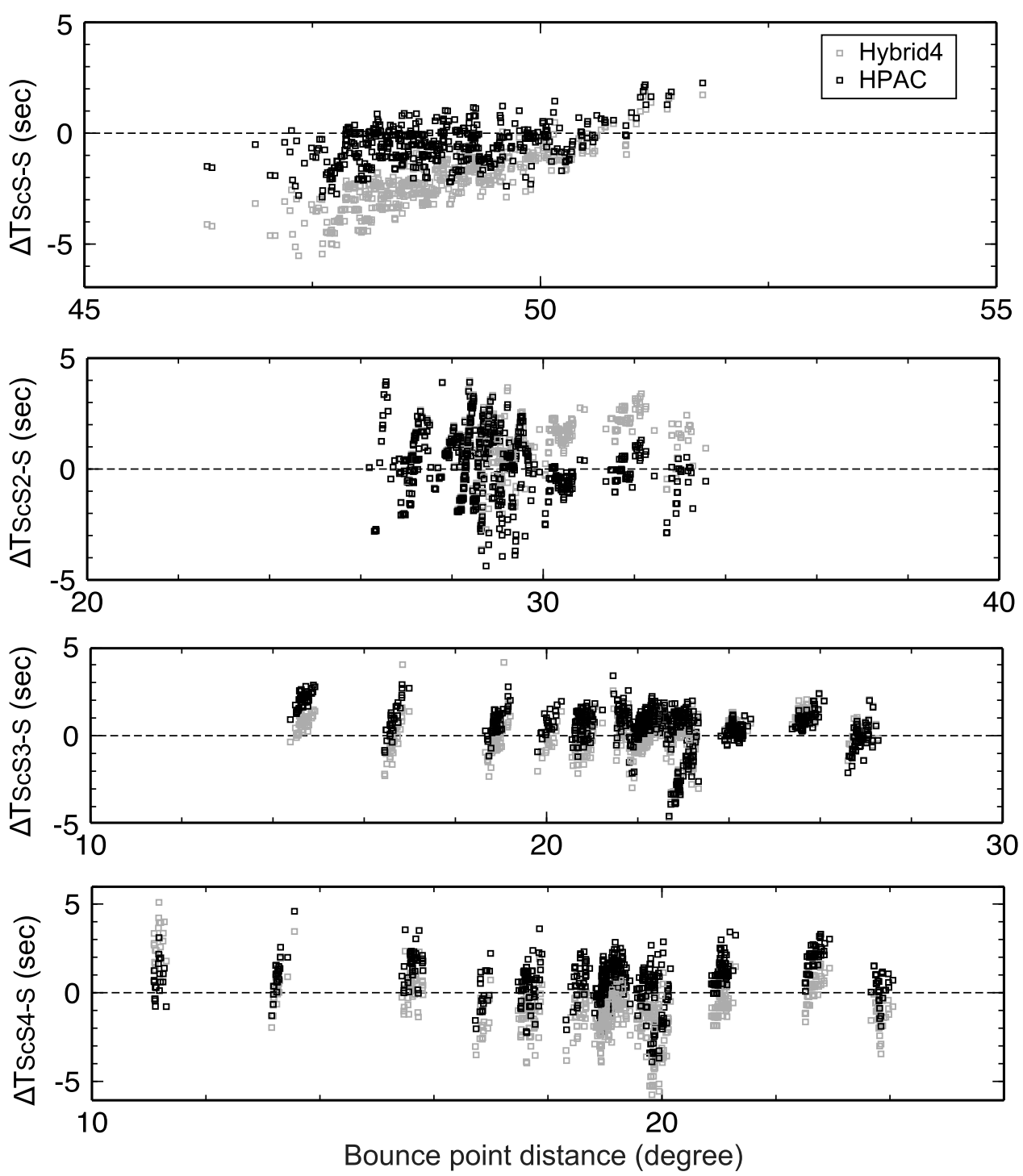

Figure 7. Travel time residuals predicted by models Hybrid4 and HPAC for all four multiples of ScS. Note the linear trends in $\mathrm{ScS}$ and $\mathrm{ScS} 2$ residuals present in model Hybrid4 but flattened out by the two ULVZs in model HPAC.

S and ScS arrivals (Figure 3). In fact, Lay et al. [2006] has also noted this complexity. A similar exercise can be performed to remove the trend observed in ScS2-S data (Figure 7), suggesting the possible existence of another ULVZ around the ScS2 CMB bounce points (Figure S5b). We locate this ULVZ to be around the source-side bounce points of $\mathrm{ScS} 2$, because the station-side bounce points clearly sample an ambient to fast mantle (Figures $1 \mathrm{~b}$ and S1).
[20] By both fitting the average travel time anomalies for all the multiples and correcting for the trends associated with $\mathrm{ScS}$ and $\mathrm{ScS} 2$, while assuming the simplest possible geometry (triangular) of CMB fine structures, we come up with a further refined model called HPAC (Figure 8a). In this model, we locate two ULVZs on the CMB with structures beyond the vicinity of these ULVZs almost identical to Hybrid4. The two resulting ULVZs are about the same peak height of

Figure 6. (a) Root-mean-square (RMS) travel time residuals from all multiples ( $\mathrm{ScS} 2$ to $\mathrm{ScS} 4)$ for different heights $(h)$ of enhancement above the CMB, where the inflation factors $(f)$ are indicated next to the symbol whose values are determined such that the algebraic mean of the travel time residuals from all three multiples is forced to be zero. Hybrid models based on S20RTS and TXBW are shown along the same axis. A smaller RMS residual implies a more balanced prediction of different $\mathrm{ScSn}$ travel time residuals. Notice the overall more reduced residuals from S20RTS-based models than from the TXBW-based ones. (b) The predicted travel time residuals of ScS2 to ScS4 plotted against their source-side CMB bounce points for the two best fit models from the two groups discussed in Figure 6a (Hybrid3 and Hybrid4, respectively). The model that best fits all ScS multiples is Hybrid4, with its structure illustrated in Figure S5a. 


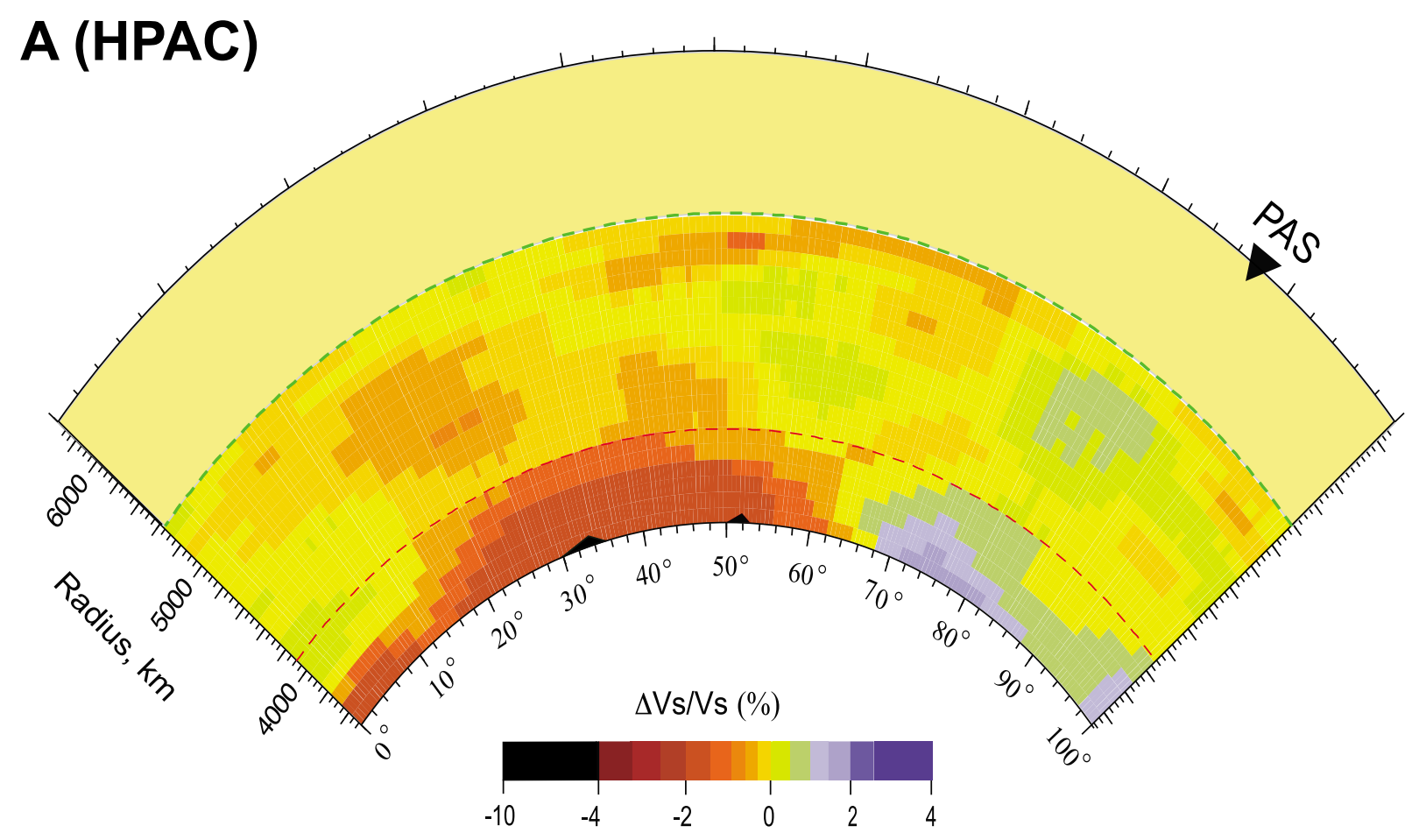

\section{B (Metastable Superplume)}

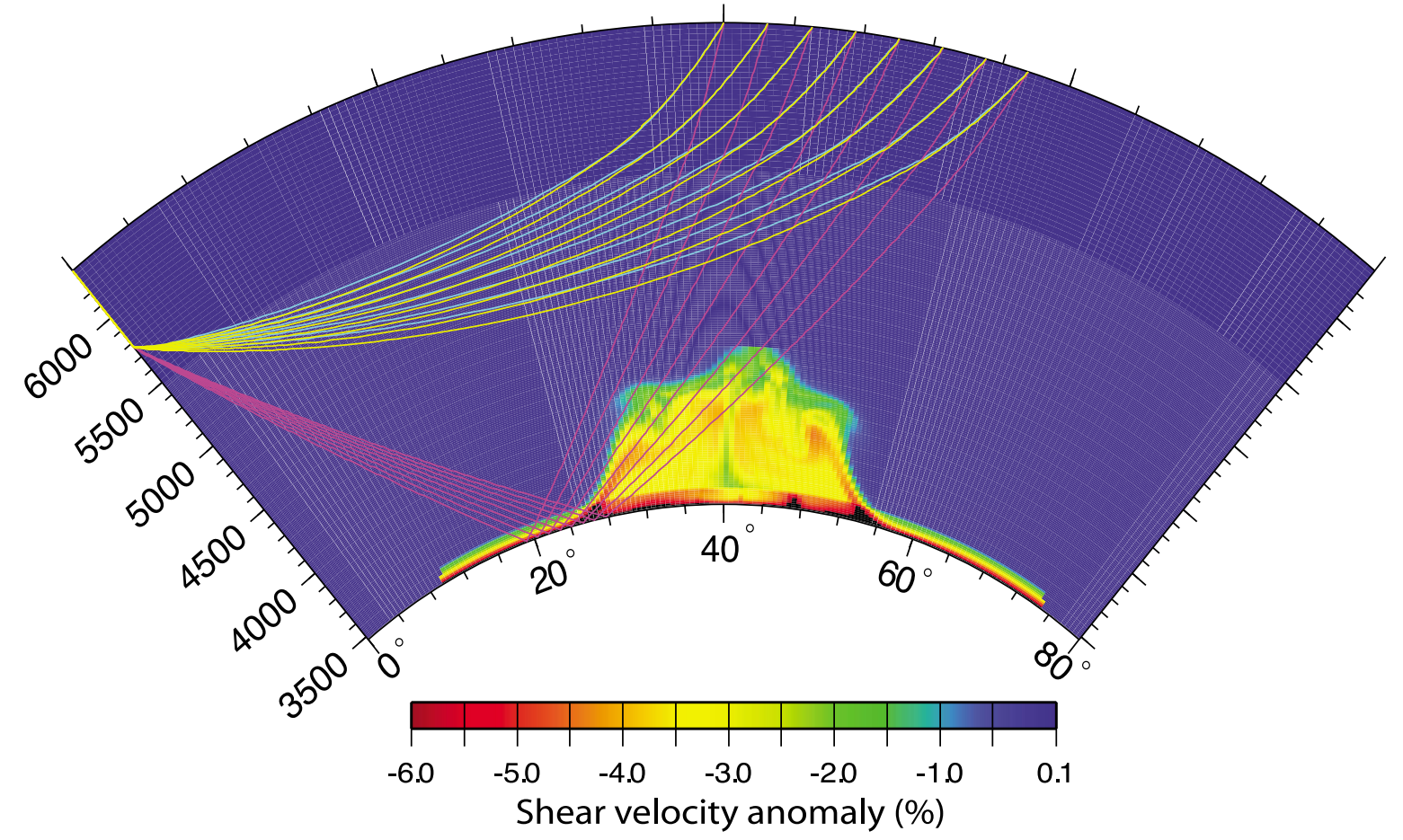

Figure 8. (a) The final hybrid model HPAC along the Pacific corridor, where the uppermost $800 \mathrm{~km}$ (above the green dashed line) is PAC06, the lowermost $600 \mathrm{~km}$ (below the red dashed line) is S20RTS inflated by a factor of 2, and the middle is the original S20RTS. Two ultra low velocity zones (ULVZ) are shown as black triangles. (b) Velocity structure of a metastable superplume generated by a geodynamic model [from Sun et al., 2007], with ScS rays sampling its edge. 
$50 \mathrm{~km}$, with a lateral maximum dimension of $150 \mathrm{~km}$ (right, sampled by $\mathrm{ScS}$ ) to $300 \mathrm{~km}$ (left, sampled by $\mathrm{ScS} 2$ ) at the bottom (Figure $8 \mathrm{a}$ ); the average velocity reductions are $10 \%$ (right) and 15\% (left), respectively.

[21] While adding an ULVZ into model Hybrid4, we have to slightly reduce the surrounding velocities in order to still predict the average travel time residuals. Interestingly, in the original tomography model S20RTS, there are two very slow anomalies right above the CMB around the $\mathrm{ScS}$ and $\mathrm{ScS} 2$ bounce points, whose lateral locations are slightly to the left of the inferred ULVZs (Figures $1 \mathrm{~b}$ and S5). We found that we have to remove these two small-scale tomography features in order for the two ULVZs to not over predict the travel time anomalies. Therefore, these small-scale tomography features and the two ULVZs appear to be similar. None of the other tomography models show these small-scale features inside the LLSVP (Figure S1), which seems to suggest that these fine structures reflect the unique constraint of the ScS multiple rays, since only model S20RTS used these phases during the inversion. This study, with a much denser sampling of the CMB region by multibouncing core phases up to ScS4, provides a cleaner image of the fine structures inside the Pacific LLSVP.

[22] The resulting lower mantle structure beneath the midPacific, therefore, is one that consists of a low-velocity province with $600 / 2000 \mathrm{~km}$ in vertical/lateral directions at an average $-2 \%$ velocity reduction, within which two sharp ULVZs are located on the CMB. This configuration resembles the seismic structure translated from a geodynamically produced metastable superplume model [Sun et al., 2007], as shown in Figure 8b, where a low-velocity dome lying above the CMB embraces several localized ultra low velocity zones at the bottom.

\section{Discussion and Conclusion}

[23] We have reviewed the $\mathrm{SH}$ shear velocity structure along a corridor across the Pacific where the lithosphere ages from $10 \mathrm{Ma}$ beneath the U.S. west coast to over $125 \mathrm{Ma}$ near Fiji-Tonga. To overcome the lack of stations, we used the multibounce phases of S and $\mathrm{ScS}$ to constrain the whole mantle structure. Except for the ends of the corridor, which are less well resolved because of the use of differential phases [i.e., Grand and Helmberger, 1984], the structure is very well sampled starting with an age of about $35 \mathrm{Ma}$, and ending at ages over $100 \mathrm{Ma}$ which includes a cross section beneath the Pacific basins [Tan and Helmberger, 2007].

[24] Three types of models were explored with two global models (S20RTS and TXBW) and a regional model (PAC06) used in a detailed validation study, and a new hybrid model constructed, HPAC. Here, we will review the construction of our model and contrast our results against other investigations.

\subsection{Model Construction}

[25] To find a 3-D whole mantle structure that fits all the multiples of $\mathrm{S}$ and $\mathrm{ScS}$, an intuitive way would be to perform a tomographic inversion. We realize, however, that model S20RTS indeed used some ScS multiples during the inversion, so the main lower mantle structures along our study profile are unlikely to be much different if a new tomography model is to be generated. On the other hand, as we show in the sections above, both $\mathrm{ScS}$ and $\mathrm{ScS} 2$ data require existence of sharp structures in the lower mantle, and detection of these features is beyond the resolving power of traditional tomographic inversion.

[26] The observation that the Pacific upper mantle structure in most tomography models displays much stronger layering than lateral variations (Figures $1 \mathrm{~b}$ and S1) suggests that the Pacific upper mantle has a simpler structure compared to its lower mantle. The 1-D model PAC06, by accurately predicting both waveforms and travel times for all $\mathrm{S}$ reverberation phases, provides a good description for the Pacific upper mantle. The tomography upper mantles are slower than PAC06 (Figures 3 and 5), as is likely due to the fact that S20RTS did not include enough S multiple phases and the long-period surface waves utilized lack resolution at depth, while TXBW may have suffered from inadequate data coverage over this region. It is the trade-off between the tomography upper and lower mantle anomaly magnitudes and the apparent 3-D pattern of the lowermost mantle beneath the Pacific that allows for a refinement of existing tomography models based on a hybrid approach as we have attempted.

[27] To obtain a good image of the lower mantle, especially the Pacific LLSVP, we take advantage of both the recently developed upper mantle model PAC06 (Figure 2) and the convergence of several global tomography models regarding lower mantle structures (Figure S1). A new regional data set consisting of multibouncing $\mathrm{ScS}$ phases, with a much denser coverage in the lower mantle than any published tomography model, provides extra constraints on the uncertain geometry and magnitude of the Pacific LLSVP. These $\mathrm{ScS}$ multiple rays are largely vertical in the upper mantle but flatten with depth (Figure 1b), indicating a greater sensitivity to vertical structures toward the CMB. The mutually orthogonal crossing rays in the lowermost mantle allow for a further refinement of the uncertain aspects of the LLSVP, especially its vertical distribution that is not well constrained by traditional tomography.

[28] The final constrained structure of the Pacific LLSVP does not seem to rely on the starting models. A comparison between model S20RTS (or TXBW) and the final hybrid model HPAC suggests that the latter clearly evolves away from these two starting tomography models. In fact, both the geometry and average velocity reduction of the bulk LLSVP in model HPAC (Figure 8a) are more close to the images resolved by several other tomography models, especially model SB4L18 and TX07 (Figure S1).

[29] The two ULVZs constrained by the linear trends of the $\mathrm{ScS}$ and $\mathrm{ScS} 2$ data are impossible to resolve through a tomographic inversion, due to the strong damping over fine details. Their detection is possible through forward modeling with a very dense seismic sampling of the lowermost mantle by multibouncing core phases that are not utilized in most tomography models. The constraints come from fitting rapid travel time variations displayed over short distances, indicating existence of sharp features. This process is largely independent of the large-scale mantle structure resolved by tomography. We have assumed a simple geometry for these ULVZs with only a few basic parameters, in order to strengthen the constraining power. With a systematic parameter search above almost the entire CMB region, the resulting 
image is likely robust, at least along the 2-D corridor of this study.

\subsection{Oceanic Lithosphere}

[30] The mobility of the lithosphere relative to the athenosphere being an essential element to plate tectonics has gotten much attention by both mineral physicists and seismologists. The earliest studies on heat flow suggested a thickening of the high-velocity lid with age, which was supported by early surface wave studies [i.e., Su et al., 1994]. Maggi et al. [2006] reached a similar conclusion, and they used only stations along the edges of the Pacific and Island observations. However, they do not find the slow zone near $55^{\circ}$ in Figure $1 \mathrm{~b}$ referred to by Ritzwoller et al. [2004] as a "reheating event" commonly found in global models. It appears that global models prefer complicated lithospheric structure beneath the Pacific Basin while regional models suggest relatively simple structures with local small-scale anomalies associated with "hot spots" [i.e., Maggi et al., 2006]. However, both approaches agree on strong anisotropic velocity models, which appear to be an essential element of oceanic lithospheres dominated by spreading ridges. In contrast, the complicated continental lithospheric structure makes it more difficult to resolve [i.e., Xue and Allen, 2007].

[31] Regional and global surface wave models indicate lithospheric thickening with age when sampling the oldest westernmost Pacific just before subduction. In contrast, experiments on water extraction at ridges starting with Hirth and Kohlstedt [1996] indicate that, perhaps, this aging effect is small. Two recent reports using different seismic data types support this conclusion. Kawakatsu et al. [2009], using receiver function analysis from borehole data beneath the oceans, find the lid thickness to be $60 \mathrm{~km}$ for ages 15 to 27 My of the Philippine plate and slightly thicker $(70 \mathrm{~km})$ just before the Pacific plate subducts beneath Japan at age 130 My. Rychert and Shearer [2009] find a Pacific average of $70 \mathrm{~km}$ although their estimate could have a bias since they were using Island stations with thicker crust. Moreover, a relatively uniform lithosphere is supported by a detailed analysis of MORB glass compositions [Presnall and Gudfinnsson, 2008]. In summary, there is mounting evidence that the upper mantle structure beneath the Pacific Basin is the simplest structure on Earth, although it is highly anisotropic [Montagner, 2002; Tan and Helmberger, 2007]. However, a uniform lid structure as proposed here would probably remain controversial until more record sections have been modeled and more tomographic models validated by waveform modeling.

\subsection{Pacific Large Low Shear Velocity Province}

[32] As discussed earlier, the upper mantle tomographic models are too slow to fit peg legs and lower mantle too fast to fit precursors. Thus, a hybrid model was developed as displayed in Figure 8a. The constrained Pacific LLSVP with a $\sim 600 \mathrm{~km}$ height and an overall velocity reduction of $-2 \%$ now appears similar to that observed beneath the South Atlantic. This configuration of the super plume seems to be confirmed by other global seismic inversions, especially the very recent one TX07 (Figure S1).

[33] Multiple tomography models suggest a relatively sharp edge near the eastern boundary of the LLSVP, where the $(\mathrm{ScS}-\mathrm{S})$ residuals have about a $5 \mathrm{~s}$ shift. By simulta- neously fitting the travel times and the linear trends in both $\mathrm{ScS}$ and $\mathrm{ScS} 2$ residuals, we find that the two very slow anomalies on the core-mantle boundary imaged by S20RTS (Figure 1b) are likely ULVZs at the base of the Pacific LLSVP (Figure 8a). Presumably, the strong change in timing when sampling such sharp structures should be apparent in precursor shifts and waveform distortion. Although the ScS phase is not ideal for verifying this prediction due to its overlapping with $\mathrm{S}$, we do notice a progressive complication of $\mathrm{ScS} 2$ and $\mathrm{sScS} 2$ waveforms for increasing distance in Figure 3, where neither PAC06 nor the tomography model S20RTS can predict this observation. A detailed study for modeling these waveform distortions is subject to future endeavor.

[34] As an independent check for the validity of the final model HPAC, we calculate the differential travel times of all $\mathrm{ScS}$ multiples against the upper mantle phase SS whose raypaths mostly stay in the upper mantle (Figure $2 \mathrm{a}$ ). In this case, we plot the predictions based on three models: PAC06, Hybrid4 and HPAC (Figure S9). Clearly, models Hybrid4 and HPAC largely remove the residuals predicted by PAC06, especially for the multiples of ScS, indicating an improved fit to these data. Furthermore, a notable difference between Hybrid4 and HPAC is that HPAC also reduces the trends observed in ScS-SS and ScS2-SS residuals, which further validates the existence of the two ULVZs as to be inside the lower mantle. On the other hand, compared to measurements with respect to $\mathrm{S}$, residuals in Figure S8 from the hybrid models show a systematic downward shift, suggesting that either all the core phases are too slow or the SS phase too fast. This could be explained by the slab structure producing the earthquakes as displayed in Figure 1b where the raypaths are distinctly different. Generally, tomography models derived by surface waves have flat slabs (e.g., Figure 1b, top) while body wave models have stronger vertical structure (Figure 1b, bottom). The former assumes CMT source locations while the latter relies on ISC P wave estimates assuming a 1-D earth. Since these locations disagree in this region, serious differences in tomography models can be expected. Although both methods relocate events in the inversion process, relocations are generally less than $5 \mathrm{~km}$ [i.e., Grand, 2002]. Since the CMT's and ISC's locations differ by up to $100 \mathrm{~km}$ for this region [Tan, 2006], it is not surprising to see offsets in predicted travel time residuals of vertical versus horizontal paths, based on existing tomography models. In short, SS is probably not that suitable as a reference phase at this stage of study.

[35] Regarding the proposed ULVZs, an independent validation comes from measuring $\mathrm{CMB}$ scattering energy with PKKP precursors. At the same location where we detect the ULVZ sampled by ScS2 (solid cylinder in Figure 1a), Rost and Earle [2010] identified a fine-scale CMB velocity heterogeneity whose dimension is on the order of $10 \mathrm{~km}$ (the white dot in Figure 1a). Our inferred ULVZ along the eastern edge of the Pacific LLSVP is similar to the lensshaped low-velocity body inferred from stacked seismograms by Lay et al. [2006] (both shown in Figure 1a). These other studies reinforce the existence of ULVZs inside the Pacific LLSVP.

[36] In conclusion, the lower mantle beneath the midPacific appears quite similar to that beneath South Africa in vertical extent although more complicated in lateral shape, 
similar to the image obtained by Houser et al. [2008]. The constrained multiscale Pacific LLSVP structure seems consistent with prediction from a metastable superplume (Figure $8 \mathrm{~b}$ ), both in the overall geometry and existence of ultra lower velocity zones (ULVZ) underneath. So far, geodynamic models that best reproduce this particular configuration of lower mantle structure with ULVZs growing from the base of a super plume are those invoking chemically distinct plume bodies [Tan and Gurnis, 2005; McNamara et al., 2010]. In this case, the CMB fine structures come from vigorous internal convection, while the giant plume can maintain its shape over geological times due to the neutrally buoyant plume head. Our study, therefore, supports the longlived nature of the two LLSVPs sitting on the core-mantle boundary, although possibly with different shapes.

\section{References}

Gaherty, J. B., and T. H. Jordan (1996), Seismic structure of the upper mantle in a central Pacific corridor, J. Geophys. Res., 101, 22,291-22,309, doi:10.1029/96JB01882.

Grand, S. P. (2002), Mantle shear-wave tomography and the fate of subducted slabs, Philos. Trans. R. Soc. London A, 360, 2475-2491, doi:10.1098/rsta.2002.1077.

Grand, S. P., and D. V. Helmberger (1984), Upper mantle shear structure of North America, Geophys. J. R. Astron. Soc., 76, 399-438.

Hirth, G., and D. L. Kohlstedt (1996), Water in the oceanic upper mantle: Implications for rheology, melt extraction and the evolution of the lithosphere, Earth Planet. Sci. Lett., 144, 93-108, doi:10.1016/0012-821X (96)00154-9.

Houser, C., G. Masters, P. Shearer, and G. Laske (2008), Shear and compressional velocity models of the mantle from cluster analysis of long-period waveforms, Geophys. J. Int., 174, 195-212, doi:10.1111/ j.1365-246X.2008.03763.x.

Kawakatsu, H., P. Kumar, Y. Takei, M. Shinohara, T. Kanazawa, E. Araki, and K. Suyehiro (2009), Seismic evidence for sharp lithosphereathenosphere boundaries of oceanic plates, Science, 324, 499-502.

Komatitsch, D., and J. Tromp (2002), Spectral-element simulations of global seismic wave propagation: I. Validation, Geophys. J. Int., 149, 390-412, doi:10.1046/j.1365-246X.2002.01653.x.

Lay, T., J. Hernlund, E. J. Garnero, and M. S. Thorne (2006), A postperovskite lens and D" heat flux beneath the central Pacific, Science, 314, 1272-1276, doi:10.1126/science. 1133280 .

Li, C., R. D. van der Hilst, E. R. Engdahl, and S. Burdick (2008), A new global model for P wave speed variations in Earth's mantle, Geochem. Geophys. Geosyst., 9, Q05018, doi:10.1029/2007GC001806.

Maggi, A., E. Debayle, K. Priestley, and G. Barruuol (2006), Multimode surface waveform tomography of the Pacific Ocean: A closer look a the lithospheric cooling signature, Geophys. J. Int., 166, 1384-1397, doi:10.1111/j.1365-246X.2006.03037.x.

McNamara, A., E. Garnero, and S. Rost (2010), Tracking deep mantle reservoirs with ultra-low velocity zones, Earth Planet. Sci. Lett., 299, 1-9, doi:10.1016/j.eps1.2010.07.042.

Melbourne, T., and D. V. Helmberger (2001), Mantle control of plate boundary deformation, Geophys. Res. Lett., 28(20), 4003-4006, doi:10.1029/2001GL013167.

Montagner, J.-P. (2002), Upper mantle low anisotropy channels below the Pacific plate, Earth Planet. Sci. Lett., 202, 263-274, doi:10.1016/S0012$821 \times(02) 00791-4$
Montelli, R., G. Nolet, F. A. Dahlen, G. Masters, E. R. Engdahl, and S.-H. Hung (2004), Finite-frequency tomography reveals a variety of plumes in the mantle, Science, 303, 338-343.

Ni, S., X. Ding, and D. V. Helmberger (2000), Constructing synthetics from deep Earth tomographic models, Geophys. J. Int., 140, 71-82, doi:10.1046/j.1365-246x.2000.00982.x.

Nolet, G., R. Allen, and D. Zhao (2007), Mantle plume tomography, Chem Geol., 241, 248-263, doi:10.1016/j.chemgeo.2007.01.022.

Presnall, D. C., and H. G. Gudfinnsson (2008), Origin of the oceanic lithosphere, J. Petrol., 49, 615-632, doi:10.1093/petrology/egm052.

Revenaugh, J., and T. H. Jordan (1991), Mantle layering from ScS reverberations: 2. The transition zone, J. Geophys. Res., 96, 19,763-19,780, doi:10.1029/91JB01486.

Ritsema, J., H. J. van Heijst, and J. H. Woodhouse (2004), Global transition zone tomography, J. Geophys. Res., 109, B02302, doi:10.1029/ 2003JB002610.

Ritzwoller, M., N. Shapiro, and S.-J. Zhong (2004), Cooling history of the Pacific lithosphere, Earth Planet. Sci. Lett., 226, 69-84, doi:10.1016/j. eps1.2004.07.032.

Rost, S., and P.-S. Earle (2010), Identifying regions of strong scattering at the core-mantle boundary from analysis of PKKP precursor energy, Earth Planet. Sci. Lett., 297, 616-626, doi:10.1016/j.eps1.2010.07.014.

Rychert, C., and P. Shearer (2009), A global view of the lithosphereathenosphere boundary, Science, 324, 495-498, doi:10.1126/science. 1169754.

Su, W., R. L. Woodward, and A. M. Dziewonski (1994), Degree 12 model of shear velocity heterogeneity in the mantle, J. Geophys. Res., 99, 6945-6980, doi:10.1029/93JB03408.

Sun, D., and D. V. Helmberger (2008), Lower mantle tomography and phase change mapping, J. Geophys. Res., 113, B10305, doi:10.1029/ 2007JB005289.

Sun, D., E. Tan, D. Helmberger, and M. Gurnis (2007), Seismological support for the metastable superplume model, sharp features, and phase changes within the lower mantle, Proc. Natl. Acad. Sci. U. S. A., 104, 9151-9155, doi:10.1073/pnas.0608160104.

Tan, E., and M. Gurnis (2005), Metastable superplumes and mantle compressibility, Geophys. Res. Lett., 32, L20307, doi:10.1029/2005GL024190.

Tan, Y. (2006). Broadband waveform modeling over a dense seismic network, Ph.D. thesis, Calif. Inst. of Technol., Pasadena.

Tan, Y., and D. V. Helmberger (2007), Trans-Pacific upper mantle shear velocity structure, J. Geophys. Res., 112, B08301, doi:10.1029/ 2006JB004853.

Tanimoto, T., and K. Prindle Sheldrake (2002), Three-dimensional S-wave velocity structure in southern California, Geophys. Res. Lett., 29(8), 1223, doi:10.1029/2001GL013486.

van der Hilst, R. D., S. Widiyantoro, and E. R. Engdahl (1997), Evidence of deep mantle circulation from global tomography, Nature, 386, 578-584, doi:10.1038/386578a0.

Xue, M., and R. M. Allen (2007), The fate of the Juan de Fuca plate: Implications for a Yellowstone plume head, Earth Planet. Sci. Lett., 264, 266-276, doi:10.1016/j.eps1.2007.09.047.

M. Chen, Department of Earth Atmospheric and Planetary Sciences, Massachusetts Institute of Technology, Cambridge, MA 02139, USA.

D. Helmberger and Y. Tan, Seismological Laboratory, California Institute of Technology, Pasadena, CA 91125, USA.

L. Liu, IGPP, University of California, San Diego, La Jolla, CA 92037, USA.

D. Sun, Carnegie Institution of Washington, 1530 P St. NW, Washington, DC 20015, USA. 